\title{
MOMENTO A PARTIR DEL CUAL DEBE EMPEZAR A COMPUTARSE EL PLAZO DE PRESCRIPCIÓN DE LA QUERELLA DE AMPARO. COMENTARIO A LA SENTENCIA DE LA CORTE DE APELACIONES DE ANTOFAGASTA DE 22 DE MARZO DE 2012. ROL 899-2011*
}

\author{
Cristián AEdo BARRENA** \\ AleXis MONDACA MiRANDA***
}

\section{1) INTRODUCCIÓN}

La sentencia de la Corte de Apelaciones de Antofagasta de 22 de marzo de 2012 recae sobre un recurso de apelación deducido en contra de la sentencia de primera instancia dictada por el Tercer Juzgado de Letras en los Civil de la misma ciudad, en autos caratulados "Giménez con Ahumada”, sobre querella de amparo, Rol 3908-2010. El tribunal de alzada, ratificando lo fallado por el juez a quo, rechazó la acción interpuesta.

La parte recurrente alegó que la apelada había ocupado y construido sobre una franja del terreno de su propiedad y posesión, equivalente a 16 metros cuadrados aproximadamente (en forma previa a su adquisición del dominio). A juicio del apelante, tales hechos harían procedente la deducción y aceptación por parte del juez competente de una querella de amparo, agregando que en la especie, se cumplían con todos los requisitos que la ley exige para la interposición de dicha acción: contaba con la posesión pacífica y tranquila de la cosa (según el artículo 918 del Código Civil el plazo de posesión debe ser de un año, sin perjuicio de la posibilidad de la agregación de posesiones); y se había perturbado la posesión, en la medida de que tales atentados (la construcción de un muro divisorio en

Fecha de recepción: 23 de noviembre de 2015.

Fecha de aceptación: 11 de enero de 2016.

** Profesor de Derecho Civil y de Derecho Romano de la Escuela de Derecho de la Facultad de Ciencias Jurídicas de la Universidad Católica del Norte, Antofagasta (CHiLe). Doctor en Derecho por la Universidad de Deusto (EspaÑa). Correo electrónico: caedo@ucn.cl

*** Profesor de Derecho Civil de la Escuela de Derecho de la Facultad de Ciencias Jurídicas de la Universidad Católica del Norte, Antofagasta (CHILE). Doctor en Derecho por la Pontificia Universidad Católica de Valparaíso (CHILE). Correo electrónico: amondaca@ucn.cl 
terrenos de la recurrente), tendrían por objeto discutir la posesión sobre el inmueble de su propiedad ${ }^{1}$.

El juez a quo consideró que la acción intentada en autos se encontraba prescrita, conforme a lo dispuesto en el inciso $1^{\circ}$ del artículo 920 del Código civil. De acuerdo con dicha norma: "Las acciones que tienen por objeto conservar la posesión, prescriben al cabo de un año completo, contado desde el acto de molestia o embarazo inferido a ella". En el mismo sentido se pronunció la Corte de Apelaciones de Antofagasta, al sostener que el plazo indicado se contaba desde el acto de molestia o embarazo, "salvo que la nueva posesión haya sido violenta o clandestina, pues en este caso el año debe computarse desde el último acto clandestino o violento, o desde que haya cesado la clandestinidad, todo lo cual es sin perjuicio de lo dispuesto en los articulos 717 a 719 del mismo texto legal que refieren la agregación y coposesión" (considerando primero del fallo de alzada).

Aplicando el precepto recientemente transcrito al caso que analizamos, en concepto de los sentenciadores de primera y de segunda instancia, la molestia o embarazo se produjo desde el momento de la adquisición de la posesión inscrita. Como consecuencia de lo anterior, según el sentenciador a quo, el único aspecto relevante sobre el que debía pronunciarse, era con relación al tiempo transcurrido desde la inscripción a favor del apelante.

En efecto, como se indicó en el considerando décimo de la sentencia del tribunal de primera instancia: "Entonces, si consideramos que ya al momento de inscribir el titulo en el Registro de Propiedad del Conservador de Bienes Raíces, y contamos el tiempo que transcurrió desde esa fecha hasta el momento de la presentación y notificación de la querella, se concluirá que ha pasado mucho más de un año completo en que podia accionar como hizo, pero fuera del plazo que dicha disposición prescribe, razón por la cual necesariamente se debe estimar que la prescripción ha operado".

En cuanto a la relevancia del fallo, consideramos que son dos los motivos para escogerlo. En primer lugar, resulta extremadamente difícil encontrar sentencias que aborden derechamente el problema del plazo de interposición de la acción de amparo posesorio y, en este sentido, juzgamos que la doctrina que envuelve la sentencia es novedosa, al entender que el plazo debe contarse desde el primer acto de embarazo. De otro lado, el repaso de los proyectos del Código civil chileno, arroja luces sobre la interpretación errónea que del precepto ha hecho la sentencia que comentaremos. Pero la segunda cuestión es a nuestro juicio todavía más importante. Si el plazo debe contarse desde el embarazo o molestia, el problema de fondo sobre el que permite una reflexión el fallo comenta-

Peñailillo Arévalo, Daniel (2006) Los bienes. La propiedad y otros derechos reales. Santiago: Editorial Jurídica de Chile, pp. 547-555. 
do estriba en determinar, cuándo se está, precisamente, frente a un acto de o molestia de la posesión inscrita y cuando en presencia de un acto de privación, en atención al sistema de garantía de la posesión inscrita (artículos 724 y 728 del CC), que es lo que protegen las acciones posesorias.

\section{2) LAS ACCIONES POSESORIAS TIENEN POR OBJETO AMPARAR AL POSEEDOR}

La posesión, no obstante ser un hecho, en atención a su innegable relevancia jurídica, es protegida por el Derecho mediante diversos instrumentos, uno de los cuales está dado por las acciones posesorias, y dentro de estas, la querella de amparo. En palabras de Alessandri, Somarriva y Vodanovic, las acciones posesorias "impiden que los particulares con prescindencia de la autoridad del Estado, se hagan justicia por si mismos y alteren, por obra de sus solos medios, la situación de hecho existente relativa a los inmuebles" 2 .

En conformidad a lo establecido en el artículo 916 del Código Civil (a igual conclusión se llega a partir del artículo 921 del Código de Bello y artículo 549 del Código de Procedimiento Civil), las acciones posesorias poseen un doble objeto: conservar o recuperar la posesión de bienes raíces o de los derechos reales constituidos en ellos ${ }^{3}$. En el caso de la querella de amparo, el objeto es el primero, esto es, tutelar la posesión asegurando la conservación de la misma.

En efecto, la querella de amparo ante la existencia o intentos de turbar o molestar al poseedor, permite: solicitar el cese de los actos constitutivos de la molestia o turbación, evitar el despojo de la posesión de continuar la producción de tales actos, pedir las seguridades correspondientes contra el perjuicio de que se trate; y la indemnización de los perjuicios producidos. De ahí que: "Toda acción posesoria está dirigida a lograr un efecto fundamental, el de volver o reintegrar la posesión al mismo estado que tenía antes de la turbación o despojo" 4 . Así lo resolvió la Corte Suprema, en la sentencia de 23 de octubre de 2014, rol Corte 3539-20145.

2 Alessandri R., Arturo, Somarriva U., Manuel, y Vodanovic H., Antonio (2005) Tratado de los Derechos Reales. Bienes. 6a Edición. Santiago: Editorial Jurídica de Chile, t. II, p. 305.

3 La excepción se encuentra en la querella de restablecimiento, la que, según el artículo 928, protege la mera tenencia ante supuestos de despojo violento. Con todo, se discute su auténtico carácter de interdicto posesorio: "No es verdaderamente querella posesoria, porque también puede ejercerla el mero tenedor; ello se desprende del inciso $1^{\circ}$ del articulo 928, que indica que la querella de restablecimiento la puede entablar cualquier poseedor y aun el mero tenedor para restablecer las cosas a su estado anterior", Kiverstein, Abraham (2006) Sintesis de Derecho civil. Bienes. 5a Edición. Santiago: La Ley, p. 247.

4 Alessandri, Somarriva, y Vodanovic (2005) 355.

5 Indicador Microjuris, MJJ39264. 
La aludida finalidad de tutela del poseedor ha sido reconocida por la jurisprudencia. Así, la Corte de Apelaciones de Santiago, en sentencia de 12 de noviembre de 1984, resolvió que la acción posesoria no prescribe, en la medida de que haya justo motivo para temer el daño que embarace o perjudique la posesión. Aunque aplicado para el caso de una querella posesoria especial (la contenida en el artículo 941, en virtud del cual " $E l$ dueño de una casa tiene derecho para impedir que cerca de sus paredes haya depósitos o corrientes de agua, o materia humedas que puedan dañarla"), no vemos razón para no aplicar este razonamiento a los supuestos propias de la querella de amparo.

Teniendo presente lo señalado en los párrafos precedentes, en la aplicación de la disciplina legislativa de las acciones posesorias deben tener presente los tribunales de justicia el señalado aspecto teleológico: la finalidad de proteger al poseedor, sin desconocer, por cierto, el plazo de prescripción de los interdictos posesorios. El artículo 920 ha presentado problemas, como en la sentencia que comentamos, cuando el acto de turbación o molestia no consiste en un acto aislado de efectos acotados en el tiempo, sino que, por el contrario, ha sido reiterado o de efectos permanentes, según profundizaremos pronto. Súmese a lo anterior la siguiente consideración: en el juicio que comentamos, el muro se construyó mientras un tercero era dueño y poseedor del inmueble respectivo, y con posterioridad a ello el recurrente adquirió el dominio de la finca.

\section{3) El PLAZO DE PRESCRIPCión SE CUENTA DESDE EL ACTO DE MOLESTIA O EMBARAZO}

\section{(3.1.)BREVE NOTICIA HISTÓRICA AL ORIGEN DEL INTERDICTO Y SU PLAZO}

No cabe duda que el origen de nuestro actual sistema de interdictos ${ }^{6}$, se encuentra en el Derecho romano. La querella de amparo posesorio se funda en el denominado interdicto "uti possidetis", es decir, "tal como poseéis" y se otorgaba por el pretor a todo poseedor cuya posesión era perturbada, con el fin de que se cesarán dichos actos, a menos que el solici-

6 La expresión “interdictos” viene del Derecho romano. Como dice Gayo 4, 140: "Vocantur autem decreta, cum fieri aliquid iubet, velut cum paecipit, ut aliquid exhibeatur aut restituatur, interdicta vero, cum prohibet fieri, velut cum praescipit, ne sine vitio possidenti vis fiat, neve in loco sacro aliquid fiat. Unde omnia interdicta aut restitutoria aut exhibitoria aut prohibitoria vocantur" ("Se llaman decretos cuando ordena que se haga algo, por ejemplo, cuando dispone que se exhoba o restituya alguna cosa. En cambio, se llama interdicto cuando prohibe que se haga algo, por ejemplo, cuando dispone que no se ejerza violencia contra el que posee sin vicio, o prohibe que se haga algo en un lugar sagrado. De ello se infiere que los interdictos se clasifican en restitutorios, exhibitorios y prohibitorios"). 
tante tuviese posesión viciosa 7 . La fórmula pretoria, como señala Ulpiano, en Comentarios al Edicto, libro LXIX, era, según D., 43, 17,1, pr.: "Ait Praetor: Uti eas aedes, quibus de agitur, nec vi, nec clam, nec precario alter ab altero possidetis, quo minus ita possideatis, vim fieri veto. De cloacis hoc interdictum non dabo; neque pluris, quam quanti res erit, intra annum, quo primum experiundi potestas fuerit, agere permitam" ("Dice el Pretor: Vedo que se haga violencia para que no poseais, como las poseéis, las casas de que se trata, y que no poseéis uno por otro con violencia, ni clandestinamente, ni en precario. No daré este interdicto respecto a las cloacas; y no permitiré que se ejercite esta acción por más que por cuanto importare la cosa, dentro del año, desde el primer momento en que haya habido posibilidad de ejercitarla") ${ }^{8}$.

Como se aprecia, en la fórmula ya se contemplaba el plazo de interposición de la acción, dentro del año. La composición, naturaleza y estructura de los interdictos se mantuvo, en esencia, hasta la codificación 9 . No obstante, el sistema de protección posesoria, dista bastante de nuestro régimen, en el sentido que la regulada en nuestro Código, como veremos, ampara la posesión sobre bienes raíces inscritos ${ }^{10}$.

En segundo lugar, nuestro Código fue innovador en relación al Code Napoleón, al incluir en sus prescripciones, la regulación de los interdictos, reservados en otras legislaciones a la regulación procesal ${ }^{11}$. Veamos

7 García Garrido, Manuel Jesús (2005) Derecho Privado Romano, t. I: Instituciones. $14^{\mathrm{a}}$ edición. Madrid: Ediasa, pp. 159-160. Como explica d'Ors, la posesión protegida por este interdicto, es la posesión pretoria. La posesión reflejaba el asentamiento sobre una parte del ager publicus, sobre el que no había dominio privado, porque su propietario era el Pueblo romano, pero el pretor protegía el asentamiento con un interdicto prohibitorio. (Véase D’Ors, Álvaro (1981) Derecho Privado Romano. 4a edición revisada. Pamplona: Ediciones Universidad de Navarra, pp. 193-194).

8 Según Gayo 4, 148-150: "Retinendae possessionis causa solet interdictum reddi, cum ab utraque parte de proprietate alicuius rei controversia est, et ante quaeritur, uter ex litigatoribus possidere et uter petere debeat. Cuius rei gratia comparata sunt uti possidetis et utruvi. Et quidem uti possidetis interdictum de fundi vel aedium possessione redditur, utrubi vero de rerum mobilium possessione. Et si quidem de fundo vel aedibus interdicitur, eum potiorem esse praetor iubet, qui eo tempore quo interdictum redditur nec vi nec clam nec precario ad adversario posideat; de re mobili, eum potiorem esse iubet, qui maiore parte eius anni nec vi nec clam nec precario ab adversario possederit; idque satis ipsis verbis interdictorum significatur". Véase también Justiniano, 4, 15, 4, quien se refiere a los interdictos de conservar la posesión en los mismos términos.

9 Para la evolución, véase Claro Solar, Luis (1979) Explicaciones de Derecho Civil y comparado, vol. IV: De los Bienes. Santiago: Editorial Jurídica de Chile, pp. 464 y ss.

10 Como dispone el artículo 728, inciso segundo: "Mientras subsista la inscripción, el que se apodera de la cosa a que se refiere el titulo inscrito, no adquiere posesión de ella no pone fin a la posesión existente". Para dar cuenta de la dificultad que representa este punto, véase, por ejemplo, Peńailillo Arévalo, Daniel (2010) Los bienes. La propiedad y otros derechos reales. Reimpresión de la 1a edición. Santiago: Editorial Jurídica de Chile, pp. 557-558.

11 El Code Napoleón reguló la posesión entre los requisitos para adquirir las cosas por prescripción, en el Libro III, título XX, capítulo II y le dedica unos pocos artículos, 2228 a 2235. Como se ha dicho, los interdictos quedaron reservados para la ley de enjuiciamiento civil. Sobre el particular, véase Colin, Ambrosio y Capitant, Henri (1923) Curso elemental de 
brevemente su tratamiento en los proyectos y la consagración definitiva, con especial énfasis en el plazo, para luego dar cuenta del debate jurídico que nos sugiere el fallo comentado.

El tratamiento de las acciones posesorias puede anotarse en el proyecto de 1853. Se regularon en dicho proyecto en el título XIII del Libro II, bajo el epígrafe "De las acciones posesorias". El parágrafo primero trata las acciones posesorias en general. Según el artículo 1068: "Las acciones posesorias deben juzgarse sumariamente, y no se concede apelación de ellas ni recurso de nulidad sino en el efecto volutivo, salvo en los casos en que alguno de los artículos siguientes ordenare otra cosa”. Conforme al artículo 1069: "Las acciones posesorias tienen por objeto conservar o recuperar la posesión. Pertenecen a todo poseedor de la misma manera que al dueño que legitima-

Derecho Civil, t. II, vol. II: De los bienes y de los derechos reales, trad. de la última edición francesa por Demófilo de Buen. Madrid: Reus, pp. 84 y ss. Algunos códigos siguieron exactamente este esquema, como el Codice Civile per lo Regno delle Due Sicilia. La posesión fue tratada, en la prescripción, Libro III, título XXI, capítulo II, artículos 2134-2141. Lo mismo ocurre con el Codice de Serdeña, de 1837. Ubica la posesión en el Libro III, título XXIV, capítulo II, artículos 2363-2370. Un cambio ya se puede apreciar, por ejemplo, el Codice Civile de Italia, de 1865, que sigue el esquema del Napoleónico, trata la posesión en el Libro II, título V. Los ocho primeros artículos siguen a la letra el Code (artículos 685 a 693), pero a partir del artículo 694 se introduce el tratamiento de los interdictos posesorios. Disponía el artículo 694: "Chi trovandosi da oltre un anno nel possesso legittimo di un immobile, o di un diritto reale, o di una universalità di mobili, vieni in tale possesso molestato, può entro l'anno dalla molestia chiede la manutenzione del possesso medessimo". Como se aprecia, se consagra así la acción destinada a conservar la posesión, es decir, una equivalente a nuestra querella de amparo. Por su parte, el artículo 695 consagra una acción restitutoria, frente al despojo de la posesiñon, en los siguientes términos: "Chi è stato violentamente od occultamente spogliato del possesso, qualunque esso sia, di una cosa mobile od immobile, puó entro el anno dal sofferto spoglio chiedere contro l'autore di esso di venir reintegrato nel possesso medesimo". Para la recuperación de la posesión, el Codice establece un procedimiento sumarísimo, como este se configuró en sus inicios en el Derecho romano y se recogió, por ejemplo, en la tradición canónica. Conforme al artículo 696: "La reintegrazione debe ordinarsi dal giudice, premezza la citazione dell'altra parte, sulla semplicé notorietà del fatto, senza dilazione e con la maggior celerità di procedure, contro qualsivoglia persona, fosse anche il proprietario delle cose de cui si è patito lo spoglio". Una regulación similar, en el sentido de admitir las acciones de retención y recuperación de la posesión, pueden encontrarse también en el Código civil austríaco, parágrafos 339-342. En el Código civil español de 1889, finalmente, la posesión fue regulada en el Libro II, título V, pero reserva una sola disposición a los interdictos posesorios, que quedaron entregados, aún antes de la vigencia del Código, a los códigos de enjuiciamiento civil. Conforme al artículo 446: "Todso poseedor tiene derecho a ser respetado en su posesión; y, si fuere inquietado en ella, deberá ser amparado o restituido en dicha posesión por los medios que las leyes de procedimiento establecen". El plazo de prescripción de estas acciones, es de un año, con arreglo al artículo 1968 № 1, aunque no indique desde cuando debe contarse ese plazo. Véase Díez-Picazo, Luis (2008), Fundamentos del Derecho Civil Patrimonial, t. III: Las relaciones jurídico-reales. El Registro de la Propiedad. La posesión. 5a edición. Madrid: Thomson Reuters, pp. 728-738. Para un análisis de la protección de estas acciones antes de la entrada en vigencia del Código civil, García Goyena, Florencio y Aguirre, Joaquín (1842) Febrero, o librería de jueces, abogados y escribanos, comprensiva de los códigos civil, criminal y administrativo. Madrid: Boix, t. VII, pp. 97-100. 
mente posee. Se extiende a la cuasiposesión"12. A su turno, el artículo 1072 prescribía: "Las acciones que tienen por objeto conservar la posesión, prescriben al cabo de un año completo contado desde el primer acto de molestia o embarazo inferido o amenazado a la posesión y conocido por el poseedor. Las que tienen por objeto recuperarla, expiran al cabo de un año completo contado desde que el poseedor anterior tuvo noticia de haber perdido posesión".

El proyecto Inédito mantiene la regulación, en el título XIII, del Libro II. Ahora, desaparece la prescripción del artículo 1068. La nueva redacción del artículo 1069, que se adapta al nuevo esquema de la posesión (desaparece la cuasiposesión), prescribe: "Las acciones posesorias tienen por objeto conservar o recuperar la posesión de bienes raices y de los derechos reales constituidos en ellos". Y, ahora, el artículo 1072 a.: "Las acciones que tienen por objeto conservar la posesión, prescriben al cabo de un año completo, contado desde el primer acto de molestia o embarazo inferido a la posesión. Las que tienen por objeto recuperarla, expiran al cabo de un año completo, contado desde que el poseedor anterior ha perdido posesión”.

La regulación contenida en el proyecto inédito es la que va a pasar al proyecto definitivo, con algunos matices de importancia para el caso que analizamos. En primer lugar, porque entre el proyecto de 1853 y el Inédito, se elimina cualquier referencia subjetiva al conocimiento que se tuviera del vicio. Ya no se exige para la de amparo el conocimiento del poseedor, ni en la de restitución, el haber tenido noticia, por parte del poseedor, de la pérdida. Por otro lado, como veremos, la forma de contabilizar el plazo, en el caso de la querella de amparo se modificó. Tanto el proyecto de 1853, como el Inédito, señalaban que el plazo de un año se contaba desde "el primer acto de turbación o molestia"13. El texto definitivo, como pasó al actual artículo 920, eliminó la referencia "primer acto", contándose, en consecuencia, el plazo, simplemente desde el "acto de molestia o embarazo inferido a ella".

\section{(3.2.) El PROBLEMA DEL PLAZO TRATÁNDOSE DE ACCIONES PERMANEN- TES DE MOLESTIA O EMBARAZO}

Los interdictos posesorios no son acciones imprescriptibles, por el contrario, su ejercicio está sujeto al cumplimiento de los respectivos plazos de prescripción liberatoria, como hemos tenido oportunidad de analizar. Cualquiera que sea la decisión del sentenciador, ella no puede

12 El mismo proyecto distinguía, siguiendo más de cerca la tradición del Derecho romano, entre la posesión y la cuasiposesión. Decía el artículo 858: "Solo las cosas corporales son susceptibles de verdadera posesión. Las cosas incorporales, sin embargo, admiten una cuasiposesión, que es susceptible de las mismas calidades y vicios que la posesión propiamente dicha".

13 En una nota manuscrita al artículo 24 del proyecto de 1853 , se lee: "Las acciones que tienen por objeto conservar la posesión, prescriben al cabo de un año completo contado desde que el poseedor notó acto de molestia o embarazo inferido o amenazado a la posesión y conocido por el poseedor". Tajadas se encuentran las palabras "que" y "poseedor notó", reemplazándose, por una letra manuscrita, por la expresión "primer acto de". 
implicar convertir una acción prescriptible en imprescriptible. Aunque esto pareciera ser una obviedad, resultará fundamental para la conclusión final del presente comentario.

Conforme al inciso $1^{\circ}$ del artículo 920 del Código de Bello, precepto que en su parte pertinente establece que las acciones de amparo prescriben en un año: "(...) contado desde el acto de molestia o embarazo inferido a ella". La disposición parece bastante clara, sin embargo, resulta bastante problemática: ¿qué debemos entender por acto de molestia o embarazo y cuándo debemos entender que se concreta este?

Reconocemos que en parte alguna el texto legal indica que el plazo de prescripción liberatoria inicia su cómputo desde que ha operado la transferencia del dominio, como lo concluyó la Corte de Apelaciones de Antofagasta. Pero antes de continuar, recordemos el primer requisito de las acciones posesorias: el sujeto activo debe ser poseedor tranquilo, no interrumpido y por un ańo a lo menos completo, según lo establece el artículo 918 del Código Civil. Dado que el caso que nos ocupa es de posesión inscrita, esta se adquiere desde la inscripción del título respectivo en el competente registro del Conservador de Bienes Raíces.

Por molestia, embarazo o turbación debe entenderse, siguiendo a Peñailillo, "Todo acto o hecho voluntario, ejecutado de buena o mala fe que, sin despojar a otro de su posesión, supone disputar o controvertir el derecho de ejercerla que pretende tener el poseedor"14. La molestia o embarazo puede ser de hecho o de derecho. Ello, sin perjuicio del problema que supone determinar la línea diferencial entre un acto de embarazo o molestia, de la efectiva pérdida de la posesión inscrita o de los derechos reales recaídos sobre inmuebles, cuestión que excede, desde luego, las pretensiones de este trabajo.

La turbación de hecho implica que: "el ataque material cometido contra la posesión ajena", mientras que la de derecho, "declaraciones o actos jurídicos que suponen inequivocamente una pretensión contraria a la posesión ajena" 15 . En el caso que nos convoca, la construcción de un muro, claramente se trata de una molestia o turbación de hecho. Ello se articula razonablemente bien con el régimen de posesión inscrita. Desde que esta se prueba mediante la inscripción y con tal de haber durado un año completo, no se admite prueba que permita impugnar la posesión, conforme al artículo 924. Con independencia de las posibles interpretaciones que la norma implica, en su relación con el artículo 925, la disposición guarda armonía con los artículos 724 y 728 del Código civil. De modo que, en el caso propuesto, un apoderamiento de hecho de la cosa, una posesión natural, podríamos decir, si se recurre a nomenclatura romana, no priva aquella parte que afecta al poseedor inscrito. En términos de Derecho registral, en consecuencia, no estaríamos en presencia de dos poseedores,

\footnotetext{
14 Peñailillo (2010) 555.

15 Alessandri, Somarriva, y Vodanovic (2005) 329.
} 
sino de un poseedor inscrito, versus un detentador que no alcanza a tener esa categoría, reconocida y amparada por el Derecho.

Ahora bien, en el caso que analizamos, el problema se presenta puesto que el acto de molestia o embarazo, la construcción de un muro en terrenos del recurrente, sucedió con anterioridad a la adquisición de la cosa por parte del amparado y, por tanto, de la inscripción del inmueble objeto de la litis, hecho que plantea un interesante problema de interpretación. En otras palabras, si el plazo de prescripción se cuenta desde la misma construcción del muro, la acción ya se encontraría prescrita al momento de inscribir a su nombre la propiedad el apelante en el registro conservatorio. Con esta conclusión se llega a un resultado injusto, motivo por el que debe rechazarse.

Pensamos que resulta bastante discutible la interpretación de la Corte de Apelaciones de Antofagasta al sostener que, a propósito de la querella de amparo, el plazo de prescripción de un año inicia su cómputo al momento de inscribir el respectivo título translaticio en el Conservador de Bienes Raíces competente, siempre que se trate de un acto con permanentes efectos perturbadores de la posesión. Al respecto, estableció la Corte de Apelaciones de Antofagasta en el considerando tercero, "En efecto, de acuerdo a las fotografías acompañadas por la propia actora, ella refiere construcciones de un muro de varios años, lo que se corrobora con la declaración del testigo presentado por la misma parte Rafael Peñafiel Pérez en cuanto él tomó conocimiento que el problema fue haber comprado cuatro de una cosa que tenía tres, ya que le faltaba el metraje, lo que evidencia que esta turbación de posesión existía antes de la adquisición del inmueble y por lo tanto, sin perjuicio de no considerar la agregación de la posesión, el año completo ya habia transcurrido, de manera que se extinguió el derecho de utilizar esta pretensión por prescripción, debiendo en consecuencia confirmar la sentencia".

Para una acertada resolución del problema debemos distinguir las siguientes situaciones respecto a dicho acto o hecho: consiste en un hecho único; existen hechos sucesivos o repetidos, pero distintos; si se trata de molestias reiteradas, pero siempre las mismas; finalmente, una sola molestia, pero resultado de varios actos progresivos desarrollados en el tiempo. En el primer supuesto no se presenta problema alguno, contándose el plazo se cuenta desde su producción. En el segundo caso, si los varios hechos son diversos, cada acto o hecho marca el punto de partida de un plazo autónomo de prescripción. En el tercer escenario, para Alessandri, Somarriva, y Vodanovic ${ }^{16}$, el plazo se computa desde el primer acto; en contra, Claro Solar ${ }^{17}$, para quien el término debe iniciarse con la producción del último acto. En el último supuesto, "El punto de partida del plazo de un

\footnotetext{
16 Alessandri, Somarriva, y Vodanovic (2005) 331-332.

17 Claro Solar (1979) 521.
} 
año será el del acto que, por representar una inequivoca contradicción a la posesión ajena, debe calificarse de molestia o embarazo inferido a ella"18. En similar sentido, Peñailillo ${ }^{19}$. Ya hemos visto que, desde el punto de vista histórico, la idea de Alessandri, Somarriva y Vodanovic, no resulta admisible.

Tratándose concretamente de la querella de amparo posesorio, en sentencia de 26 de junio de 2008, la Corte Suprema determinó el alcance que debe dársele al plazo de prescripción: "La interpretación del articulo 920 del Código Civil que más se condice con la voluntad del legislador, es aquella que postula que el plazo de prescripción debe contabilizarse en el caso de las acciones que tienen por objeto conservar la posesión, desde la fecha del último acto de molestia o embarazo que ha experimentado el poseedor de parte del turbador $y$, en el caso de las acciones que tienen por objeto recuperar la posesión, desde el último acto de violencia o desde que haya cesado la clandestinidad".

No obstante, consideramos que los hechos que originaron el juicio que analizamos no están comprendidos en ninguno de los supuestos mencionados por la doctrina hasta el momento. En efecto, el acto de molestia o embarazo consiste en la construcción de un muro, pero ello aconteció varios años antes de la adquisición del dominio y posesión del mismo por parte del recurrente. Esto es, se trata de un acto único, pero con efectos permanentes.

Por una simple conclusión lógica, si la turbación ha sido permanente, no ha dejado por ello de producirse respecto del apelante. No puede aceptarse una interpretación que conduzca a afirmar que el nuevo poseedor nunca podría ejercer la acción. En este sentido, mal sería que el derecho permitiese que un dueño y poseedor que ha adquirido el dominio de un bien inmueble quedase privado de la tutela proporcionada por la querella de amparo solo en atención a que el único y permanente acto de turbación o molestia se ha producido en un período de tiempo en el que el dueño y poseedor era otra persona; esta conclusión es exigida por la finalidad protectora que tienen los interdictos posesorios.

Ahora bien, tampoco sería adecuado que el nuevo poseedor, basándose exclusivamente en que el acto de molestia operó con anterioridad a su adquisición del dominio, no obstante el tiempo transcurrido, pudiese siempre intentar la querella de amparo. Es evidente que una acción prescriptible no puede ser transformada por una interpretación de los textos legales que la disciplinan en imprescriptible. En consecuencia, debemos encontrar el necesario punto medio.

\footnotetext{
18 Alessandri, Somarriva, y Vodanovic (2005) 332.

19 Peñailillo (2010) 550.
} 
Teniendo en cuenta todo lo anterior, proponemos lo que sigue: es incontrovertible que el plazo de prescripción de la querella de amparo es de un ańo contado desde el acto de molestia o turbación. En el caso en que exista un único poseedor no se presentan dificultades. Pero en la especie, el querellante es un nuevo poseedor, el que no puede verse afectado negativamente por la desidia del anterior poseedor quien no dedujo en tiempo y forma la pertinente acción posesoria. Concluir lo contrario significaría declarar que los nuevos adquirentes están obligados a soportar las perturbaciones a su posesión, incluso aunque estas sean permanentes, tan solo porque los anteriores poseedores no solicitaron en sede judicial el amparo a que tenían derecho. Así las cosas, entendemos que para determinar el plazo de prescripción de un año para el nuevo poseedor debemos distinguir dos situaciones, considerando que debe haber estado a lo menos en un año de posesión y la posibilidad de accesión de posesiones.

Si opera la accesión de posesiones, desde el primer día de la nueva posesión, inicia el cómputo del plazo de prescripción. Si no hay agregación de posesiones, debe transcurrir un año desde la inscripción del título para que comience el plazo de prescripción. En el fallo que comentamos, sin embargo, la I. Corte no hace estas necesarias prevenciones. Dijo en el considerando cuarto: "Que ninguna consideración tiene la reflexión del apelante en cuanto quedaría imposibilitado para interponer el respectivo interdicto con la exigencia del legislador en cuanto debe ser poseedor tranquilo y no interrumpido durante un año completo, porque el propio articulo 551 del Código de Procedimiento Civil permite agregar la posesión de sus antecesores, lo que tampoco tendría trascendencia, desde que -como se dijo-, el artículo 920 del Código Civil hace extensivo los artículos 717 a 719 del mismo cuerpo legal, de manera que siempre ha podido el poseedor incorporar o agregar la posesión de sus antecesores, pudiendo estar un día en su posesión y no obstante interponer la querella posesoria porque lo que interesa para los efectos de la prescripción es el acto de molestia o embarazo, que en este caso concreto ocurrió cuando ha pasado ya mucho más de un año y por ende se hace procedente declarar la prescripción pedida por la demandada".

Dados estos supuestos, entendemos que el plazo de prescripción de un año para el nuevo poseedor, debe comenzar a regir desde que pueda dar por acreditada la posesión con arreglo al artículo 924, es decir, que el año completo exigido en el artículo 920, se cuente una vez transcurrido el plazo de un año contado desde la inscripción. No parece razonable que, en un caso como el que presentamos, se entienda que el ańo completo del artículo 924 pueda acreditarse con la agregación de la posesión, conforme al artículo 717, porque nos encontraríamos con la paradoja de que el plazo nacería prescrito. Con todo, ello supone negar la acción, en un caso como el que analizamos, si esta se deduce antes del año de la inscripción; si el actor decidiera tener por acreditado el requisito con las posesiones 
anteriores, recordemos que dicha agregación, voluntaria, se debe realizar con sus calidades y vicios. Uno de tales vicios sería, por tanto, la caducidad del ejercicio de la querella de amparo, aunque reconocemos que la solución no resulta del todo satisfactoria: es claro que el Código no resuelve adecuadamente el problema de las molestias permanentes.

Una posibilidad heterodoxa sería la de solucionar el problema a semejanza de la solución que la doctrina ha propuesto para el denominado daño moral permanente. En responsabilidad civil, en efecto, el daño moral permanente ha permitido entender que no resulta aplicable el plazo de prescripción de los 4 años del artículo 2332, pero que, en todo caso, no puede intentarse la acción pasados diez años contados la perpetración de los hechos, en atención a que es el plazo máximo que nuestro sistema contempla para subsanar las situaciones jurídicas ${ }^{20}$, pero evidentemente, exportar esta fórmula, plantea serios problemas de coherencia con el texto.

Con la primera interpretación propuesta se respeta tanto el texto normativo que establece el plazo de prescripción y la forma de computarlo, como la finalidad de tutela de los interdictos posesorios, puesto que no se priva al nuevo poseedor de la protección de la querella de amparo, y tampoco se permite un abuso de esta al transformarla en la práctica en una acción imprescriptible.

20 Véase Barros Bourie, Enrique (2009) Tratado de Responsabilidad Extracontractual. Reimpresión $1^{a}$ edición. Santiago: Editorial Jurídica de Chile, p. 925. 